\title{
A qualitative study of participant engagement with a weight loss intervention
}

Elizabeth Holdsworth ${ }^{1}$, Nicki Thorogood ${ }^{1}$, Annik Sorhaindo ${ }^{1}$, Kiran Nanchahal ${ }^{1}$.

${ }^{1}$ Faculty of Public Health and Policy, London School of Hygiene \& Tropical Medicine, 15-17

Tavistock Place, London WC1H 9SH

Correspondence to: Elizabeth.holdsworth@1shtm.ac.uk

Ms. Elizabeth Holdsworth is a Research Fellow of Public Health and Policy at London School of Hygiene \& Tropical Medicine.

Dr. Nicki Thorogood is a Senior Lecturer in Sociology at London School of Hygiene \& Tropical Medicine.

Ms. Annik Sorhaindo is a PhD candidate of Public Health and Policy at London School of Hygiene \& Tropical Medicine.

Ms. Kiran Nanchahal is a Senior Lecturer of Public Health and Policy at London School of Hygiene \& Tropical Medicine.

\section{Funding}

The CAMWEL RCT was supported by Camden Primary Care Trust (NHS Camden). The funding source had no role in the design or conduct of the study; collection, management, analysis, or interpretation of the data; preparation, review, or approval of the manuscript.

\section{Conflict of interest}

The authors declare no conflict of interest.

\section{Acknowledgments}


We thank the study participants and NHS Camden for their support of this study, and Jessica Datta and Claire Thompson for their comments on the manuscript. 